\title{
REPENSAR LA UNIVERSIDAD: UNA PEDAGOGÍA PARA EL PRESENTE DESDE PAULO FREIRE
}

\author{
Rethinking the University: A Pedagogy for the Present from \\ Paulo Freire
}

\author{
Karla Mabel Bolo Romero \\ Universidad Femenina Sagrado Corazón, Perú \\ https://orcid.org/0003-1494-1752 \\ kbolo@unife.edu.pe
}

\begin{abstract}
RESUMEN
En esta investigación se pregunta si el pensamiento de Paulo Freire tiene vigencia para abordar los problemas contemporáneos de la educación y sus implicancias sociales y culturales dentro de la Universidad. Se centraliza en los aspectos que han interpelado la forma de educar y su ligazón con los aspectos sociales. Para lo cual se analizan las principales categorías pedagógicas de Freire en su "Pedagogía del oprimido", como son concientización, educación bancaria y libertad, como también se examina el carácter social de su "Pedagogía", su apertura a los problemas raciales y de género, y su ligazón dentro de la Universidad.
\end{abstract}

\section{Palabras clave:}

Pedagogía del oprimido, concientización, educación bancaria, libertad, dialéctica opresores-oprimidos.

\section{ABSTRACT}

This research considers if Paulo Freire's thought has validity to address contemporary problems of education and its social and cultural implications within the University. It focuses on the aspects that have influenced on the way in which education is conducted and its link with social facets. To this end, the main pedagogical categories Freire presents in his "Pedagogy of the oppressed" are analyzed, such as awareness, banking education and freedom, as well as the social character of his "Pedagogy", his openness to racial and gender problems, and its connection within the University.

\section{Keywords:}

Pedagogy of the oppressed, awareness, banking education, freedom, oppressoroppressed dialectic 


\section{INTRODUCCIÓN}

Freire, el máximo pedagogo el siglo XX, nos ha legado distintas aristas desde donde leer su pensamiento, para ser exactos cinco modelos de pedagogía entrelazadas entre sí: del oprimido, de la esperanza, de la autonomía, de la indignación $y$ de la tolerancia. Si bien no se desligan, si suman nuevos derroteros teóricos para leer el movimiento de la educación. Nos interesa mucho la primera pedagogía de Freire, la del oprimido, debido al contexto actual en que vivimos, es decir, una coyuntura de difuminación, erosión, exaltación de los márgenes y orillas, asentada en la educación. Estos vientos endebles se arraigan a la educación, pero además pueden servir de gafas borrosas que no permitan analizar los problemas reales que nos aquejan. El filósofo heideggeriano peruano e importante estudioso de la educación, Victor Li Carrillo, nos dice que hay que: "(...) resolver la confrontación entre el hombre y el mundo y para humanizar la confrontación derivada entre el hombre y otros hombres. La relación hombre/mundo impone al hombre construir su mundo, su mundo humano, siempre revocable y rectificable. (...)"'. (Li Carrillo, 2008, 180). Salir del esquema deshumanizador o resolver la confrontación entre el hombre y el mundo, como dice Li Carrillo, presupone romper con el aspecto opresor de la educación. Freire, creemos nosotros, nos brinda las herramientas pedagógicas para lograr esas pretensiones. Veamos más de cerca estos aspectos.

\section{1) la pedagogía del oprimido para el siglo XXI}

¿Es vigente la Pedagogía del oprimido y la forma educativa que presentó Paulo Freire? Para responder esta pregunta, vale la pena realiza una breve propedéutica sobre las categorías centrales de Freire, para después delinear ciertas nociones e intuiciones a modo de respuesta a la cuestión. En primer lugar, Freire critica la ya conocida Educación Bancaria. ¿Qué es la educación bancaria? En lenguaje hegeliano, es la visión estática del movimiento desligado de la dialéctica del sujeto y el objeto. Nos exhorta Freire al respecto que: "La concepción 'bancaria' (...) en el momento en que se fundamenta sobre un concepto mecánico, estático de la conciencia y el cual, por esto mismo, transforma a los educandos en recipientes, en objetos, no puede esconder su marca necrófila". (Freire, $2005,89)$. Esta crítica de Freire resulta muy vigente para muchos espacios educativos tanto de colegios como de universidades, ya que en estos espacios "educativos" la visión crítica brilla por su ausencia. La educación "(...) no admite, para un educador, un momento donde solo, en su biblioteca o en su laboratorio, conoce, y otro donde alejado de este simplemente narra, diserta, o expone lo que conoce. En el momento mismo en que investiga, como un sujeto cognoscente, frente al objeto cognoscible, no está solo, sino aparentemente". (Freire, 2005, 89). La educación, por el contrario, debe ser práctica para la libertad. Hegel decía que, mientras más conocemos el mundo, más lo comprendemos y con ello alcanzamos una determinación más para la libertad, sin lo anterior, sin el conocimiento, la libertad sería imposible. Freire nos dice en sus propios términos que (...) la educación como práctica de la libertad no es la transferencia o la transmisión del saber ni de la cultura, no es la extensión de conocimientos técnicos, no es el acto de depositar informes o hechos en los educandos, (...) Para nosotros, la educación como practica de libertad, es (...) una situación verdaderamente gnoseológica. Aquella en que el acto 
cognoscente no termina en el objeto cognoscible, ya que se comunica a otros objetos igualmente cognoscentes. (Paulo Freire, 2005, 60)

Por lo tanto, los objetivos de Freire son reanimar la relación del sujeto y el objeto hacia la libertad. Esto sería, por lo mismo, negar la opresión. Como nos dice el antropólogo colombiano Eduardo Restrepo sobre la concepción pedagógica de Freire: "(...) el oprimido es clave en su concepción sobre el funcionamiento del poder. El oprimido no es solo aquel que soporta la dominación, la opresión es una relación dialéctica entre opresores y oprimidos, en la que estos últimos incorporan la lógica opresora. (...)". (Restrepo, 2010, 55). Por lo tanto, Freire busca salir de este esquema estático de opresión, para construir una dinámica de la libertad. En los propios términos de Freire: "Solo en su solidaridad, en que lo subjetivo constituye con lo objetivo una unidad dialéctica, es posible la praxis autentica. Praxis que es reflexión y acción del hombre sobre al mundo para transformarlo. Sin ella es imposible la superación de la contradicción opresoroprimido. (Freire, 2005, 51). ¿Cómo entonces debe educar el educador? En primer lugar, debemos desechar las herramientas categoriales no dinámicas de educador educado, porque si las vemos en la dinámica, ambas se complementan y hasta desaparecen una en la otra. Esto significa romper con la estática y la jerarquía establecida. La tarea del educador es problematizar junto al educando. En los propios términos de Paulo Freire: "La tarea del educador entonces, es la de problematizar a los educandos, el contenido que mediatiza y no, la de disertar sobre él, darlo, extenderlo, entregarlo, como si se tratase de algo ya hecho, elaborado, acabado, terminado (...)" (Freire, 2005, 95-96). En su sexta carta a quien pretende enseñar, Freire nos dice que "Una vez inaugurado el proceso testimonial por parte del educador, poco a poco los educandos se van asumiendo también. Esta participación efectiva de los educandos es señal de que el testimonio de la educadora está funcionando". Al romper con el esquema opresor de educar bancarizado, tenemos otras vías pedagógicas que recorrer, pero ¿cómo lograr esta meta?

En este momento del camino propedeútico, cabe introducir la categoría de "concientización". La concientización se puede definir como el proceso que, basado en la relación educador-educando como síntesis, allana el camino para la liberación. Dice Freire que "Toda prescripción es la imposición de la opción de una conciencia a otra. De ahí el sentido alienante de las prescripciones que transforman a la conciencia en receptora en lo que hemos denominado conciencia que "aloja" la conciencia opresora". (Freire, 2005, 45). La concientización siempre es liberación y está ligada con la educación contra la opresión. Además, la concientización, como proceso pedagógico, tiene un margen político qué se basa en el diálogo. Para entender mejor esta cuestión, cabe citar a uno de los estudiosos más destacados de Paulo Freire, nos referimos al filósofo peruano Augusto Salazar Bondy en su libro La educación del hombre nuevo:

Concientizar es la tarea educativa que hace tomar al individuo conocimiento crítico de su situación real en el contexto socioeconómico, permitiéndole reconocerse como un ente social responsable que forma parte de un proceso histórico en el cual está ineludiblemente inserto y que lo emplaza a participar activamente 
en él. El desconocimiento de este hecho o su evasión constituye el concepto polarmente opuesto de alienación. Concientizar es, pues, desalienar. (Salazar, 1975, 47)

Por lo tanto, la alienación dentro de la sociedad actual se contrapone a la libertad, ya que en la primera el educando es sometido a un esquema bancarizado, donde no tiene voz, ni participación, sino que solo es un recipiente para llenar de fríos conocimientos. Por eso es válida la afirmación de Salazar Bondy cuando dice que Concientizar es, pues, desalienar y, agregamos, educar es el camino necesario. Esto también para los problemas raciales y de género que nos aquejan.

\section{2) Pedagogía del oprimido y universidad}

Actualmente, las humanidades y saberes poco útiles están en un serio peligro a nivel mundial. El capitalismo mercantiliza no solos los objetos y sujetos, sino las relaciones intersubjetivas más íntimas, los símbolos tradicionales y las costumbres milenarias de los pueblos originarios. La forma educativa no se desliga de estos esquemas. Todo tiene un valor de cambio, todo es medido desde un esquema de mercado. Como bien ha expuesto el destacado filósofo mexicano Gabriel Vargas Lozano "(...) en un mundo en donde predomina la violencia, la irracionalidad y la enajenación se requiere que la filosofía y las humanidades en general participen activamente en la reconfiguración de una sociedad más justa democrática y humana (Vargas E Patiño, 2016, 115). El filósofo peruano Salazar Bondy analiza el desarrollo de la educación en el Perú de los años 70's y relaciona el nexo que problematizamos entre la mercantilización y la educación:
(...) empresas productivas interesadas en mejorar la capacitación de sus trabajadores (...) cursos de capacitación laboral, so pretexto de una exigente preparación técnica, descuidan no solo los aspectos de cultura general no ligados directamente con el adiestramiento correspondiente, sino que abierta y sistemáticamente excluyen todo tópico que signifique cuestionamiento del orden social (Salazar, 1975, 25).

No solo las humanidades corren peligro, sino que todos los ámbitos se tiñen de matices positivistas, con miras a un tecnicismo cada vez más creciente. La forma de educar no escapa de estas esferas sociales, al contrario, debe enfrentarse constantemente a estos detalles. ¿Cómo es posible en este contexto pensar la educación?

El núcleo educativo actualmente es la universidad, por lo tanto, vale la pena examinar la universidad y sus limitaciones, además de intentar brindar algunas ideas desde la perspectiva de Paulo Freire.

Para Freire el papel de la Universidad no es omniabarcante, por ende, cabe pensar la autonomía. Nos dice Freire en una entrevista titulada El papel de los intelectuales en la universidad:

Existe una cierta especificidad de lo político en el ámbito académico, pero no es posible que exista una política académica que baile sobre la historia, sobre lo social, sobre lo político en general; por eso a mi juicio es inviable una universidad que esté más allá y más arriba del sistema social y político de la sociedad; toda política académica tiene fundamentalmente un punto 
de referencia con el sistema global. (Freire, 2017, 10).

Freire nos invita a pensar la Universidad situada o tejida en sus complejas relaciones desde donde ha sido creada y desde donde se desarrolla. De tal modo, cada universidad tiene sus particularidades diversas a otras. La universidad se liga a los sucesos externos, depende de estos, se retroalimenta, fuera de la universidad, no está sometido o homogeneizado con la universidad, por lo tanto, el educando requiere autonomía o en cierto modo pensar una educación nuclearizada. Augusto Salazar Bondy llamó nuclearización a la siguiente idea:

El sistema nuclear, en contraste con el escolar, es la comunidad en plan educativo, el conjunto de la población en un ámbito territorial, con todos sus servicios, escuelas y también agencias de salud, comercio e industria, representantes del gobierno local y el poder central, colaborando con los padres de familia y los maestros de la gestión educativa. (Salazar, 1975, 41).

Por consiguiente, las reflexiones que extraemos aquí, son que la universidad se desarrolla desde una serie de presupuestos sociales, es desde esta que deben emanar sus ideas y problemas. La nuclearización apunta a re-vincular estos lazos que con las burocracias y jerarquías se han ido oxidando o deshaciendo. Del mismo modo, la universidad no puede abarcar todo el espacio del sujeto educado, dicho de otro modo, la autonomía de los estudiantes se desarrolla en esferas sociales fuera de la universidad, si la universidad se desvincula de estas otras esferas, estará lejos de comprender el todo del educando y, con ello, los saberes se habrán producido desligados. La universidad actual se basa más en el esquema escolar que busca sistematizar conocimientos y brindarlos tal cual, pero cंestos saberes provienen de nuestra propia realidad o, al contrario, se gestaron desde otras latitudes o tiempos? La ligazón de la universidad y la sociedad es un problema que ponemos a discusión.

Otro punto crítico que se desarrolla dentro del tejido social de la Universidad es el del colonialismo educativo o el racismo. No solo porque se ejerzan en la interacción social, sino porque todos los saberes, comportamientos y praxis son permeados desde esas formas. El tema del colonialismo también es esbozado por Freire. La educación para él debe salir del esquema colonizador y racista. Esto implica una pedagogía menos jerárquica, de abajo para arriba. "¿cómo salir de la herencia colonial y cómo crear un nuevo sistema educativo, si sabemos que la educación es una dimensión de la práctica social y que ésta es como un río en el que una de las afluentes es la lucha por la producción, otra la lucha de clases y una más la actividad científica creadora (que existe en una sociedad determinada, en función de cómo estas fuerzas productivas se organizan)? ¿Cómo reformular radicalmente la educación colonial sin haber hecho todavía la reestructuración radical de la infraestructura del país?" (Freire, 2007, 22). Otra vez aparece la concepción totalizadora de Freire, donde vincula todos los aspectos necesarios para poder cambiar la forma de educación. Por ejemplo, en Cultura y liberación sobre la pedagogía colonizadora:

De ahí que la pedagogía del colonizador no pueda ser una pedagogía para la liberación del colonizado. Sería una ingenuidad 
-casi angelical- que el colonizado pidiese al colonizador que haga una pedagogía para él. Aquí la educación colonial no podría tener otro objetivo que la desafricanización del africano. Esta educación desafricante, selectiva, busca asimilar a los africanos a su sistema, para lograr lo que Fanon llamó "negro de alma blanca". Ésta es la herencia que dejaron los colonialistas. (Freire, 2007, 20-21)

El segundo apunte que realizamos a las formas educativas actuales dentro de la universidad en general es que se desarrolle el aspecto colonial de los conocimientos, dejando poco espacio a los saberes tejidos en la misma sociedad peruana. Además de criticar lo negro con máscaras blancas, que apuntaba Fanon, vale la pena poner en agenda la construcción alienada y alienante de subjetividades ligados a los colores de piel o al origen nacional del educador y del saber que se brinda, que en muchos espacios todavía se construyen saberes vistos desde Europa. Si bien Freire criticaba la opresión en general, su propuesta educativa de la esperanza se liga a romper con las formas raciales de dominación y sus expresiones educativas.

Finalmente, el tercer punto que buscamos apuntar es el de las relaciones de género dentro de la Universidad. Si bien, deseamos examinar desde Freire, resulta un tanto complicado realizarlo, porque el educador brasileño no profundizó en estas relaciones. Sin embargo, existen lecturas que sugieren que Freire sí pensó el tema, porque pensaba en una emancipación universal. Verone Lane Rodrigues, especialista en Freire, nos sugiere interesantes líneas en su texto Pedagogía de la oprimida. Epistemología femenina. "El problema de las mujeres -y por supuesto, el de todos los grupos dominados y oprimidos- es el de superar las astucias "universalizadoras" y "absolutizadoras" de los dominantes sin crear contra-astucias también con pretensiones universales y absolutas". (Verone, 2007, 161). A la hora de educar esto se liga con la visión freireriana de superación de la opresión para lograr la libertad. La educación no debe reproducir las pretensiones de un género imponiéndose, ya sea en la relación del educador-hombre frente al educandomujer, o a los educandos de diversos géneros. Repensar el papel de la mujer en las relaciones educativas brinda luces en muchos espacios vacíos que han sido poco examinados. ¿Por qué en la mayoría de clases hay más mujeres? ¿En el proceso educativo el hombre y la mujer tienen las mismas posibilidades? Verona nos dice que: "No es el simple cambio de las posturas sociales, o sea, la sustitución del discurso masculino por el femenino que llevará a un real compromiso con la transformación social, que debe incluir a todas y todos en un mundo más humanizado y más justo". (Verone, 2007, 150). Por ende, examinar las relaciones de género en la educación, no significa la absolutización de alguno de los polos, sino la liberación de la opresión educativa para todos. La concientización del hombre nuevo en general, debe tomar en cuenta las relaciones de género que muchas veces no colocan en el mismo plano a la mujer y el hombre. Romper con la opresión, por consiguiente, también presupone y demanda pensar estos tres puntos: 1) el aspecto social desde y fuera de la universidad y los nexos entre ambos. 2) El aspecto colonial de la educación. 3) Las relaciones de género en las formas educativas. 


\section{CONCLUSIONES}

Por lo examinado, podemos concluir que la universidad es una institución educativa necesaria para poder desarrollar al ser humano, por lo tanto, también de sus expresiones. Hemos analizado las categorías de Freire para buscar desde estas una opción para pensar la universidad desde el presente. Además, podemos concluir que resulta vital comprender tres problemas centrales que se manifiestan en las universidades contemporáneas: 1) social; 2) colonial; 3) género. Hemos intentado apuntar algunas ideas generales sobre estos tres aspectos dificultosos que aquejan actualmente la forma de educar, para así alcanzar espacios de las relaciones educativas que pueden obstruir o forzar la formación de los estudiantes.

\section{REFERENCIAS BIBLIOGRÁFICAS}

Freire, P. (2005). Pedagogía del Oprimido. Paulo Freire. CD. Siglo Veintiuno

Freire, P. (1982). ¿Extensión o comunicación? La concientización en el medio rural. Siglo veintiuno editores. Freire, P. (2004). Pedagogía de la autonomía. Paz e terra SA.

Freire, P. (2007). El papel de los intelectuales en la universidad. En Paulo Freire: praxis de la utopía y la esperanza. Universidad de Colima.
Freire, P. (2007b). Cultura y liberación. En Paulo Freire: praxis de la utopía y la esperanza. Universidad de Colima.

Freire, P. (2008). Cartas a quien pretende enseñar. (Ampliada y mejorada). Siglo Veintiuno.

Li, V. (2008). Enseñanza de la filosofía. Editorial Universidad Garcilaso de la Vega.

Restrepo, E. (2010). Inflexión decolonial. Fuente conceptos $y$ cuestionamientos. Instituto de Estudios Sociales y Culturales Pensar

Rodrigues, V. (2007). Pedagogía de la oprimida. Epistemología femenina. En Paulo Freire: praxis de la utopía y la esperanza. Universidad de Colima. Salazar, A. (1975). La educación del hombre nuevo. Paidos

Salazar, A. (1995). Dominación y Liberación. Escritos 1966-1974. Fondo editorial San Marcos.

Salazar, A. (2013). Historia de las ideas en el Perú contemporáneo. Fondo Editorial del Congreso del Perú.

Vargas, G. E Patiño, L. (2016). La difusión de la filosofía ces necesaria? D. F. Editorial Torres Asociados.

Yáñez, J. (2007). Paulo Freire: praxis de la utopía y la esperanza. Universidad de Colima.

Fecha de recepción: 20/11/2020 Fecha de aceptación: 05/12/2020 
